\title{
Cost-effectiveness of self-management in asthmatics: a 1-yr follow-up randomized, controlled trial
}

\author{
F. Gallefoss*, P.S. Bakke
}

Cost-effectiveness of self-management in asthmatics: a 1-yr follow-up randomized, controlled trial. F. Gallefoss, P.S. Bakke. (C) ERS Journals Ltd 2001.

ABSTRACT: Patient education in asthma can improve outcome but cost-effectiveness has not been widely assessed. The aim of the present study was to carry out a costeffectiveness analysis of patient education in asthmatics in a 12-month follow-up.

The authors randomly allocated $\mathbf{7 8}$ asthmatics to a control or intervention group after they had received ordinary outpatient consultation care. Intervention consisted of two 2-h group sessions followed by 1-2 individual sessions administered by a nurse and a physiotherapist. Self-management was emphasized. Effectiveness was expressed in terms of quality of life and forced expiratory volume in one second (FEV1). Doctor visits, days off work, dispensed pharmaceuticals, hospital admissions, travel costs, time costs and educational costs were recorded.

The control and intervention groups induced mean total costs of Norwegian Krone (NOK) 16,000 and 10,500 per patient, respectively. A 10-unit improvement in St. George's Respiratory Questionnaire total score and a 5\% improvement in FEV1 in the intervention group were associated with a saving of NOK 3,400 and 4,500, respectively, compared to the control group. The number needed to educate (NNE) to make one person symptom free was associated with a saving of NOK 12,200. The results were robust to realistic changes in the assumptions upon which they were based.

It could be concluded from this study that patient education in asthmatics in a 12month follow-up improved patient outcomes and reduced costs. Eur Respir J 2001; 17: 206-213.

The prevalence of asthma in North-America and Europe is about $5 \%$ of the adult population with strong evidence for increasing incidence [1]. Asthma results in a significant burden being placed on public health budgets in these countries [2-6], and the potential for public savings is high. Health economical evaluations are therefore, strongly warranted $[7,8]$.

Patient education in asthmatics can improve patient outcome and has been recommended in several clinical guidelines for asthma [9-12]. However, previous costeffectiveness assessments after asthma education are rare and of limited applicability to clinical practice. KAUPPINEN et al. [13] reported an improvement in the forced expiratory volume in one second (FEV1) at higher costs without performing a sensitivity analysis and Neri et al. [14] described the cost of one day of admission being prevented.

The present asthma education programme has been shown, in a 12 month follow-up, to improve quality of life, level of lung function [15] and compliance to inhaled corticosteroids [16] as well as reducing GP consultation rates and absenteeism from work [17] due to asthma. Based on these data, estimated the costeffectiveness ratios of patient education choosing St. George's Respiratory Questionnaire (SGRQ) total score, FEV1 and number needed to educate (NNE) to make one person symptom free as clinically important effectiveness measures were calculated.

To the best of the authors' knowledge no previous
*Section of Pulmonary Medicine, Medical Dept, Vest-Agder Central Hospital, Kristiansand, Norway and ${ }^{\#}$ Dept of Thoracic Medicine, University Hospital of Bergen, Bergen, Norway.

Correspondence: F Gallefoss, Lungeseksjonen, Medisinsk avdeling, VestAgder Sentralsykehus, 4604 Kristiansand, Norway.

Fax: 4738073327

\section{Keywords: Asthma}

cost-effectiveness analysis

economics

patient education

randomized controlled trial

Received: April 212000

Accepted after revision October 122000

This work was supported by the Norwegian Medical Association's Fund for Quality Improvement. report on patient education in asthmatics has evaluated how many patients need to be educated in order to obtain a given effect. NNE is equivalent to the number needed to treat (NNT), that has been strongly advocated in clinical trials [18].

The study was conducted in the societal perspective, implying that all costs are accounted for, irrespective of who pays.

\section{Subjects and methods}

The study design and educational programme have recently been described in detail [15-17].

\section{Study design}

Seventy-eight consecutive symptomatic asthmatics were included in the study May 1994-December 1995, after having received ordinary consultation care at the outpatient chest clinic at a medium sized somatic hospital in Southern Norway. At inclusion, they gave written signed consent and were then randomly allocated to an intervention group or a control group using random number tables received from an external statistician in sealed envelopes. The patients in the intervention group first received an education programme, and were then followed by their general practitioners (GPs), while the patients in the control group were transferred directly to their GPs (fig. 1). 


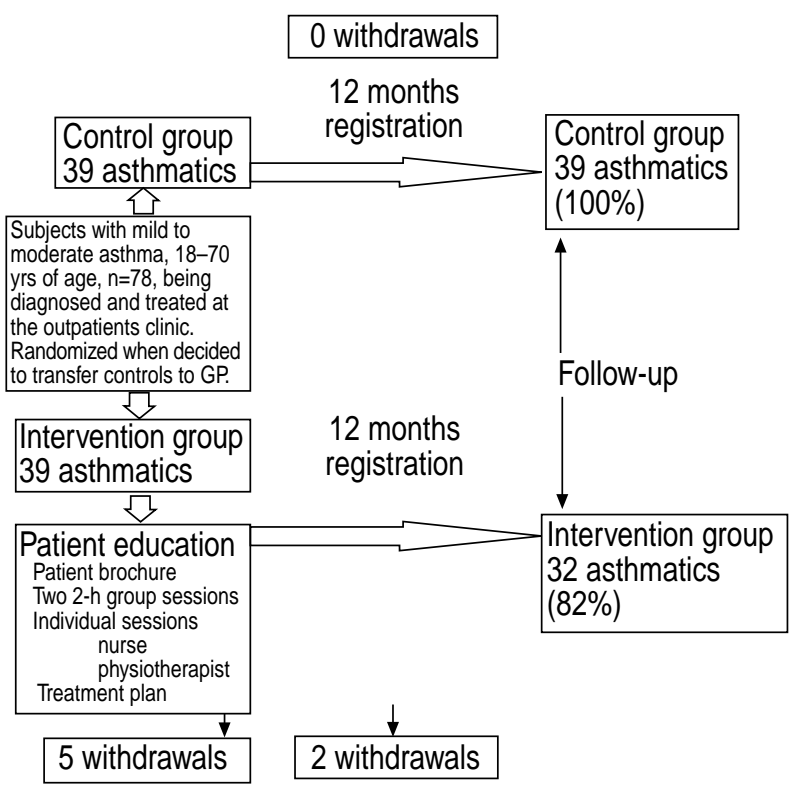

Fig. 1. - Scheme of study design and withdrawals.

After $1 \mathrm{yr}$, all the patients were invited to a follow-up examination. The availability and organization of GP care was similar in the two groups.

Eligible asthmatics were $18-70$ yrs of age, and did not suffer from any other serious disease. The primary inclusion criterion for asthmatics was a prebronchodilator $\mathrm{FEV} 1 \geqslant 80 \%$ of predicted ( $\%$ pred) value [19]. Furthermore, either a positive reversibility test [19], a documented $20 \%$ spontaneous variability (peak expiratory flow (PEF) or FEV1) or a positive methacholine test (PD20). A positive reversibility test was defined as $\geqslant 20 \%$ increase (FEV1 or PEF) from baseline after inhalation of $400 \mathrm{ng}$ salbutamol. The inclusion rate amongst the eligible patients was $92 \%$ (78 out of 85 ).

\section{Educational programme}

None of the randomized patients had earlier received organized asthma education. The education programme consisted of two 2-h group sessions and $1-2 \mathrm{~h}$ of individual counselling administered both by a nurse and a physiotherapist (fig. 1). Elementary pathophysiology of asthma, asthma drug mechanisms, how to cope with asthma and principles for self-management were covered. An individual self-management plan aimed at encouraging early change of medication during episodes of asthma attacks was issued. The intervention group also received a specially-made 19-page booklet co-ordinating the information given during the educational sessions.

\section{Outcome variables}

Effectiveness measures. Both Health Related Quality of Life (HRQoL) and symptom data have been recommended as important effectiveness measures in the management of asthma and have been found to correlate well with pulmonary function measures [5]. Other less important alternatives of comparison, as previously published [16, 17], could have been tested, but recommendations for cost-effectiveness analyses advise unidimensional designs [20].

Health Related Quality of Life. Both HRQoL and symptom free days have also been advocated in cost-effectiveness analyses [5, 21]. HRQoL was assessed at baseline applying four simple questions translated from the Omnibus interviews [22]. The answers were dichotomized at the signs " $\boldsymbol{\nabla}$ " shown later, to reveal outcomes of clinical importance [5, 20]. Wording of the questions and the preprinted alternatives for answering were: 1) The last year my chest trouble has become: Worse, unchanged or $\boldsymbol{\nabla}$ better; 2) The last two weeks I have had asthma symptoms during the day: All the time, $2-4$ times a day, every day, 2-3 times a week or $\boldsymbol{\nabla}$ more seldom; 3) The last two weeks I have had asthma symptoms during the night: Waken 3 times or more, waken 1-2 times or $\boldsymbol{\nabla}$ do not wake up; 4) My asthma has the last two weeks restricted me from doing what I want: To a great extent, medium extent or $\boldsymbol{\nabla}$ little or no extent. Regarding the responses to these questions, the two groups were comparable at baseline [15]. The same four questions were repeated at the 1-yr follow-up.

At the 1-yr follow-up, patients completed the SGRQ [23], a validated and disease-specific quality of life instrument consisting of 76 weighted items. A "Total" score is calculated, providing a global estimation of the patients' respiratory health. The total scores ranges $0-100$, a score of 100 indicating maximum disability. A difference of four units indicates a slight clinical effect, while a difference of eight or twelve units indicates moderate or very good clinical effects, respectively. Thus, a difference of 10 units in SGRQ total score between treatment groups at the 1-yr follow-up, is of clinical significance.

Spirometry. Spirometry was performed prior to randomization and at 12 months follow-up by standard methods [19] using a Jaeger MasterLab Body Box (Würzburg, Germany). The patients were told to abstain from bronchodilators for $6 \mathrm{~h}$ before testing.

Costs. The costing was based on utilization of care and unit costs (IUS\$ = 7 Norwegian Krone (NOK), 1994). Costs, as presented, were rounded to the nearest NOK 100 unless the original cost was $<100$. Exact costs were used when statistical tests were performed. Patient co-payments were included in the costs. Direct costs in this study are defined as costs borne by the healthcare system, community and family. Indirect costs are defined as productivity loss and time costs borne by the individual, family, society or by the employer.

The cost of asthma education included patient copayments and reimbursement costs according to the fee schedule of the National Health Insurance (NHI) covering both group sessions and individual sessions. Market prices were applied for the Peak Flow meter, the cost of premises and the patient brochure.

The cost of hospital care for asthma was based on the Norwegian Diagnosis Related Groups (DRG) 
reimbursement rates [24], assuming that all admissions fell in diagnosis group 4 [24], rate number 97 (NOK 10,880 per stay).

The patients reported monthly GP visits due to asthma [17], using standardized registration forms and self-addressed, stamped envelopes. Detailed information on date, time and duration of consultation, name of the doctor, pulmonary function tests and personal costs by the patient was received, and the costs set according to the NHI fee schedule [25]. The public block grant for GP clinics was included, at the time NOK $365100 \cdot \mathrm{yr}^{-1}$, which with an average consultation rate of 4,010 consultations $\cdot \mathrm{yr}^{-1}$ [26], assuming each patient consultation amounted to NOK 91. Pulmonary consultant visits were costed according to the NHI fee schedule [25]. The cost of pharmaceuticals according to the Anatomical Therapeutic Chemical (ATC) Classification Index, group R03 and H02A B [27], was based on monthly reports from the local pharmacies recording current market prices for dispensed medication.

The cost of time for those employed was set equal to the national hourly wage rate (NOK 106.2) [28]. Time costs were applied for both seeking healthcare and asthma education, assuming 2 and $2.5 \mathrm{~h}$ (including waiting and travel time) for GP and pulmonary physician visits, respectively. The individual educational sessions at the same day were assumed to last for $1 \mathrm{~h}$ (plus $1.5 \mathrm{~h}$ travel time) including $40 \mathrm{~min}$ individual nurse and physiotherapist sessions, thereby adjusting for 20 min waiting time per session. The cost of lost leisure for those not employed was assumed to be zero, but alternative assumptions were explored in the sensitivity analyses.

The number of days absent from work due to asthma were reported monthly, and valued according to the national average daily wage rate (NOK 567) [28].

Patients' travel costs in relation to medical care and asthma medication were calculated on the basis of bus fares from the patients' residence.

No discounting was undertaken since the costs and consequences were contained within $1 \mathrm{yr}$.

Cost-effectiveness analysis. Cost-effectiveness analyses relate monetary costs to a measure of clinical effectiveness. A cost-effectiveness ratio is the difference in costs between two alternatives to the difference in effectiveness between the same two alternatives ( $\delta$ costs/ $\delta$ effects). A positive ratio implies a positive effect at a certain cost. A negative numerator and a positive denominator imply a positive effect at a lower cost, a so-called dominant strategy [29]. An adjusted cost-effectiveness ratio relates to the cost per outcome of clinical significance, for example the cost per 10-unit improvement in SGRQ total score or 5\% improvement in FEV1.

\section{Sensitivity analyses}

One-way sensitivity analyses were undertaken to explore how robust the results were to changes in the basic case assumptions, i.e. the assumptions upon which they were based. The low estimate for production loss was calculated to be hourly wage-rate times $70 \%$ and the high estimate times $130 \%$ [30], thereby accounting for example, for social costs (employer tax etc).

A threshold analysis on the most important cost assumption (production loss) was undertaken in order to identify the "break even" point, i.e. the value that made the total costs in the two groups equal [31].

\section{Statistics}

Regarding the binary outcomes from the four quality of life questions, the concept of NNT which is the estimated number of patients who need to be treated with a new treatment rather than the standard treatment, for one additional patient to benefit was applied [18]. In this study this expression was changed to NNE. NNE is the reciprocal value of Absolute Risk Reduction $(\mathrm{ARR})$ i.e. $1 / \mathrm{ARR} . \mathrm{ARR}=\mathrm{Pi}-\mathrm{Pc}$, where $\mathrm{Pi}$ is the proportion with the desirable outcome in the intervention group and $\mathrm{Pc}$ is the proportion in the control group. For example the NNE to make one person experience "A better year" is calculated as follows: $\mathrm{NNE}=1 /(0.81-0.43)=1 / 0.38=2.63$.

The $95 \%$ confidence interval (CI) for the difference between two population proportions (ARR) were constructed around the difference between the observed proportions $\mathrm{Pi}$ and $\mathrm{Pc}$ in the two samples of sizes ni and nc. The standard error of this difference $=$ square root $[($ Piqi/ni) + Pcqc/nc) $]$ where $q i=1-$ pi and $q c=1-P c ~[18]$.

The Chi-squared test or Fisher's exact test was applied for binary outcomes, while the Mann-Whitney U-test was applied for the cost data due to skewedness.

A cost/concentration curve shows the cumulative costs plotted against the cumulative number of patients, starting with the patient with the highest costs and ending with the patient with the lowest cost.

All analyses were performed using the SPSS version 8.0 (SPSS Inc, Chicago, USA). The Norwegian Data Inspectorate and the regional ethical committee approved the study.

\section{Results}

\section{Effectiveness measures}

The study groups were comparable at baseline (table 1), including use of medication as previously

Table 1.-Baseline characteristics of the asthmatics included in the study

\begin{tabular}{lcc}
\hline & Control group & Intervention group \\
\hline Subjects n & 39 & 39 \\
Sex, Male & $8(21)$ & $15(39)$ \\
Age yrs & $44 \pm 12$ & $41 \pm 12$ \\
Smoking habits & & \\
$\quad$ current smokers & $13(33)$ & $9(23)$ \\
Employed & $24(62)$ & $29(74)$ \\
FEV1\% \%red & $95 \pm 17$ & $93 \pm 13$ \\
FVC \% pred & $105 \pm 15$ & $104 \pm 12$ \\
FEV1\% & $78 \pm 9$ & $75 \pm 8$ \\
\hline
\end{tabular}

Data are presented as $\mathrm{n}(\%)$ or mean \pm SD. FEV1: forced expiratory volume in one second; FVC: forced vital capacity; $\%$ pred: per cent predicted. FEV $1 \%$ was calculated according to the following, $(\mathrm{FEV} 1 / \mathrm{FVC}) \times 100$. 
Table 2. - Health related quality of life according to St. George's Respiratory Questionnaire (SGRQ), change in forced expiratory volume in one second $\left(F E V_{1}\right)$ and response to four quality of life questions at 12 month follow-up

\begin{tabular}{|c|c|c|c|c|c|c|}
\hline & $\begin{array}{l}\text { Control } \\
\text { group }\end{array}$ & $\begin{array}{l}\text { Intervention } \\
\text { group }\end{array}$ & Difference & $\begin{array}{l}95 \% \text { CI for } \\
\text { the difference }\end{array}$ & OR & $\mathrm{p}$-value \\
\hline Subjects $\mathrm{n}$ & 39 & 32 & & & & \\
\hline \multicolumn{7}{|l|}{ SGRQ total scores at the } \\
\hline & $36.5 \pm 18$ & $20.2 \pm 15$ & 16.3 & $8.2-24.4$ & & $0.0002 *$ \\
\hline FEV1 change in $\mathrm{mL}$ & $-83 \pm 38$ & $112 \pm 39$ & 195 & $11-377$ & & $0.038^{*}$ \\
\hline FEV1 change in $\%$ & $-2.7 \pm 12$ & $3.4 \pm 13$ & 6.1 & $0.2-12.1$ & & $0.043^{*}$ \\
\hline \multicolumn{7}{|l|}{$\begin{array}{l}\text { Percentage answering that } \\
\text { they had }\end{array}$} \\
\hline A better year & 43 & 81 & & $1.8-16.5$ & 5.5 & $0.002^{\#}$ \\
\hline Symptom free days & 36 & 81 & & $2.4-22.7$ & 7.4 & $0.001^{\#}$ \\
\hline Symptom free nights & 60 & 94 & & $2.0-47.8$ & 9.9 & $0.001^{\#}$ \\
\hline No impact on daily life & 62 & 88 & & $1.2-14.7$ & 4.3 & $0.02^{\#}$ \\
\hline
\end{tabular}

Data are presented as mean \pm SD. CI: confidence interval; *: independent-samples t-test; ${ }^{*}$ : Chi-squared test; OR: odds ratio.

reported [16], 96\% were on inhalation steroids at randomization and two-thirds of the asthmatics were employed. At follow-up, the SGRQ total score was 16.3 units lower (HRQoL was better) in the educated group, compared to controls $(\mathrm{p}<0.001)$. The lung function (FEV1) improved by $6.1 \%$ in the intervention group compared to the noneducated $(\mathrm{p}<0.05$, table 2$)$. There was a need to educate $2.6,2.2,2.9$ and 3.9 persons for one person to experience a better year with regards to the chest condition, symptom free days, symptom free nights and to have no impact in daily life, respectively (all p-values $\leqslant 0.02$, fig. 2).

\section{Costs}

The mean direct cost in the educated group was NOK 5,900, the indirect costs NOK 4,600, in total NOK 10,500 (table 3). The corresponding costs for the control group were NOK 4,000, 11,900 and 16,000. Reduced absenteeism from work in the educated group explained most of the difference in total costs. The production loss accounted for $75 \%$ and $32 \%$ of the total

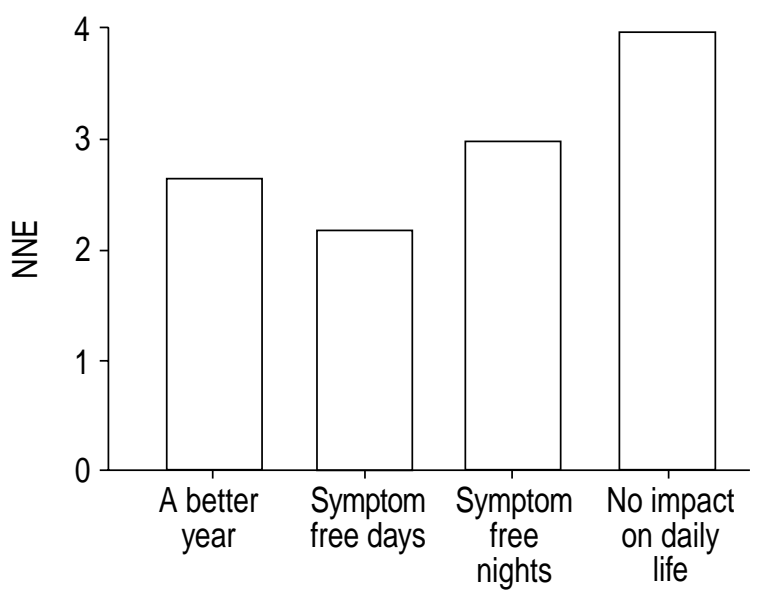

Fig. 2. - Number needed to educate (NNE) to make one person have 4 types of outcome. $95 \%$ confidence intervals: a better year: 1.7-5.9; symptom free days; $2-22$; symptom free nights $1.9-$ 6.3 ; no impact on daily life: $2.1-20$.

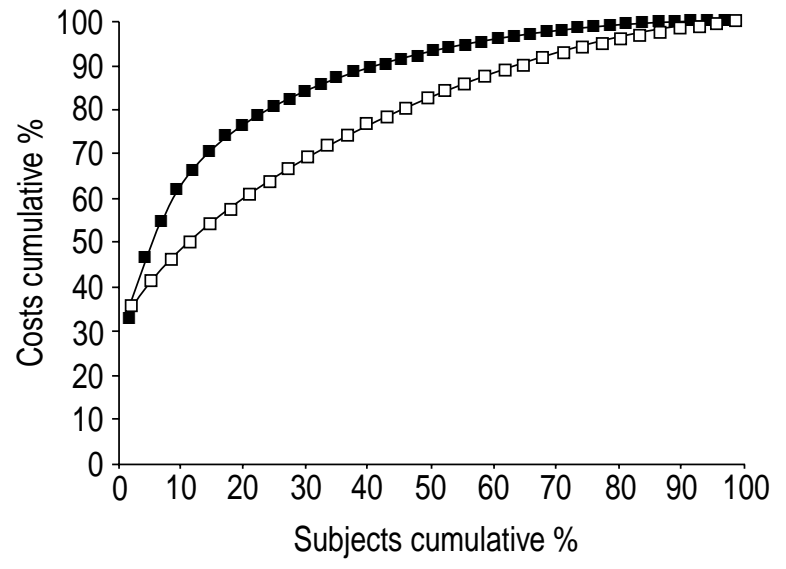

Fig. 3. - The cost/concentration curve showing the cumulative costs plotted against the cumulative number of patients. $\mathbf{\square}$ : control; $\square$ : intervention.

costs in the control and intervention groups, respectively.

There was an uneven distribution of costs. According to the cost/concentration curve (fig. 3), the most costly patient in each group accounted for more than $30 \%$ of the total group costs. For the educated group, $20 \%$ of the most resource intensive patients accounted for about $60 \%$ of the total costs compared to about $75 \%$ in the control group. Nine and $23 \%$ induced costs higher than NOK $15,000(p=0.11$, Fisher's exact test $)$ in the education and control group, respectively.

\section{Cost-effectiveness analyses}

According to the baseline case assumptions, the total costs were lower in the educated group than in the control group. This implies that asthma education incurred lower costs and better outcomes. If indirect costs were disregarded, the costs were higher in the educated group (table 3 ). With all costs included, the cost-effectiveness ratios were NOK $-3,400$ per 10 unit improvement in SGRQ total score, NOK $-4,500$ per $5 \%$ improvement in FEV1 and NOK -12,200 per symptom free patient (table 4). 
Table 3. - Direct, indirect and total costs (NOK) per patient during a 12 month follow-up for the intervention and control groups

\begin{tabular}{|c|c|c|c|c|c|}
\hline & \multicolumn{2}{|c|}{ Control } & \multicolumn{2}{|c|}{ Intervention } & \multirow[t]{2}{*}{ p-value* } \\
\hline & Mean \pm SD & Median 25/75 $\mathrm{P}^{\#}$ & Mean \pm SD & Median 25/75 $\mathrm{P}^{\#}$ & \\
\hline \multicolumn{6}{|l|}{ Cost items } \\
\hline Patient education programme & 0 & 0 & $900 \pm 50$ & $900(900 / 1000)$ & $<0.001$ \\
\hline Peak flow meter & 0 & 0 & 200 & 200 & $<0.001$ \\
\hline Pharmaceuticals/drugs & $3300 \pm 3100$ & $2400(1900 / 4500)$ & $3700 \pm 3400$ & $2400(1000 / 5600)$ & 0.703 \\
\hline GP visits & $600 \pm 900$ & $200(0 / 800)$ & $200 \pm 500$ & $0(0 / 200)$ & 0.001 \\
\hline Pulmonary physician visits & $55 \pm 200$ & $0(0 / 0)$ & $52 \pm 200$ & $0(0 / 0)$ & 0.555 \\
\hline Hospital admissions & $\overline{0}$ & 0 & $700 \pm 2700$ & $0(0 / 0)$ & 0.116 \\
\hline Travel costs doctor visits & $63+89$ & $22(0 / 88)$ & $21 \pm 55$ & $0(0 / 22)$ & 0.001 \\
\hline Travel costs educational programme & 0 & 0 & $100 \pm 34$ & $100(100 / 100)$ & $<0.001$ \\
\hline Total direct costs & $4000 \pm 3800$ & $3400(1100 / 5500)$ & $5900 \pm 4800$ & $4100(2500 / 8800)$ & 0.054 \\
\hline Patient time cost for education programme & $\overline{0}$ & 0 & $1200 \pm 600$ & $1400(1100 / 1400)$ & $<0.001$ \\
\hline Patient time cost for doctor visits & $300 \pm 700$ & $0(0 / 200)$ & $100 \pm 500$ & $0(0 / 0)$ & 0.044 \\
\hline Production loss & $11600 \pm 33100$ & $0(0 / 5100)$ & $3400 \pm 16700$ & $0(0 / 0)$ & 0.038 \\
\hline Total indirect costs & $11900 \pm 33500$ & $200(0 / 6400)$ & $4600 \pm 17300$ & $1400(1100 / 1500)$ & 0.302 \\
\hline Total costs & $16000 \pm 35400$ & $5400(1500 / 11100)$ & $10500 \pm 20500$ & $5800(4000 / 10100)$ & 0.510 \\
\hline
\end{tabular}

\section{Sensitivity analyses}

The direct and total cost differences did not vary overtly when choosing the most unfavourable assumptions for the variables (table 5). Since production loss had the largest impact on the total cost difference, the corresponding low and high production loss estimates also had the greatest influence on the sensitivity analyses, varying, the total cost difference between NOK 3,000 and 8,000 (table 5). If the cost of production loss was set to $25 \%$ of what was assumed in the baseline case analysis, the two patient groups would have the same average costs per patient (NOK 7,000).

\section{Discussion}

The present study indicates that patient education in mild to moderate asthmatics improved health, and at the same time saved costs. A 10-unit improvement in SGRQ total score and a 5\% improvement in FEV1 in the intervention group were associated with a saving of NOK 3,400 and 4,500, respectively, compared to the control group during a 12 month follow-up. The NNE to make one person symptom free was 2.2 and for each patient becoming symptom free after patient education there was a concomitant saving of NOK 12,200. A oneway sensitivity analyses indicated satisfactory robustness of the main conclusions.

To the best of the authors' knowledge the present study is the first to assess cost-effectiveness ratios of patient education in asthmatics referring to HRQoL, lung function and NNE and to report better outcomes at lower costs; a negative cost-effectiveness ratio. Generally in medicine, there is a tendency to be accustomed to positive cost-effectiveness ratios; better outcomes at higher costs. Previously, KAUPPINEN et al.
[13] reported a 5.5\% improvement in FEV1 at $17 \%$ higher costs in the intervention group 12 months after patient education, compared to controls.

The assumption that the last three specific quality of life questions reflect an average of the study period may be opposed, since the authors asked for the occurrence of asthma symptoms and impact on daily life during the last two weeks. However, in the SGRQ, several of the subscore components also relate to the patient's current state. It is likely that the last two weeks represent a typical average for the study period. Furthermore, no differentiation was carried out in the questionnaire between those reporting symptoms $<2-3$ times per week and those being symptom free. In figure 2 these were all interpreted as being "symptom free". Thus, the data presented on daily symptoms, might be an overestimate with regard to symptom control, but in clinical practice many physicians would argue that having symptoms $<2-3$ times per week is a satisfactory symptomatic relief in asthmatics.

A limitation of the present study is that the SGRQ scores were only obtained at the 12-month follow-up as opposed to FEV1 and the four asthma symptoms, which were also recorded at baseline. Hence, it was not known whether there was a drop or increase in SGRQ scores in the control group from baseline to follow-up. The difference in SGRQ scores is reported as an improvement, assuming comparable quality of life at baseline. This assumption is supported by the fact that the intervention and control groups were comparable at baseline for all variables recorded [15-17]. Nevertheless, the cost-effectiveness analysis of the SGRQ scores should be interpreted with caution.

Other methodological issues concerning bias and confounding have been thoroughly discussed and statistically tested, when possible, in previous reports from the same study [15-17]. The skewed distribution 


\begin{tabular}{lcc}
\hline & Direct costs & Total costs \\
\hline Cost-effectiveness ratios* & & $-5493 / 16.3=-337$ \\
Difference in SGRQ total scores at 1-yr follow-up & $1839 / 16.3=113$ & $-5493 / 195=-28$ \\
FEV1, change in mL & $1839 / 195=9.4$ & $-5493 / 6.1=-901$ \\
FEV1, change in \% & $1839 / 6.1=301$ & $-3400 / 10$ \\
Adjusted cost-effectiveness ratios*,\#,+ & $1110 / 10$ & $-2800 / 100$ \\
Difference in SGRQ total score at 1-yr follow-up & $900 / 100$ & $-4500 / 5$ \\
FEV1, change in mL & $1500 / 5$ & \\
FEV1, change in \% & $1839 / 38=48$ & $-5493 / 38=-145$ \\
Cost-effectiveness ratio/per \% of patients having: & $1839 / 45=41$ & $-5493 / 45=-122$ \\
A better year & $1839 / 34=54$ & $-5493 / 34=-162$ \\
Symptom free days & $1839 / 26=71$ & $-5493 / 26=-211$ \\
Symptom free nights & & \\
No impact on daily life & 4800 & -14400 \\
The cost of making one person have ${ }^{*, \#}$ & 4100 & -12200 \\
A better year & 5400 & -16100 \\
Symptom free days & 7100 & -21100 \\
Symptom free nights & & \\
No impact on daily life & & \\
\hline
\end{tabular}

*: incremental cost (NOK)/unit of improvement; ${ }^{*}$ : the main outcome cost-effectiveness ratios are rounded off to the nearest NOK 100; ${ }^{\top}$ : the cost of making one person have $=\left(\right.$ direct or total costs difference $\times$ number needed to educate); ${ }^{+}:$an adjusted cost-effectiveness ratio relates to the cost per outcome of clinical significance. SGRQ: St. George's Respiratory Questionnaire; FEV1: forced expiratory volume in one second; NOK: Norwegian Krone.

of costs implies that few persons accounted for a large impact on average costs (fig. 3). This observation seems common when considering cost evaluations for asthma $[13,14,32,33]$. For example, within the USA, $10 \%$ of asthmatic patients accounted for $44 \%$ of the total medical costs of treating the condition [34].

Regarding cost-effectiveness analyses in patient education, an interesting topic would be how to maintain effectiveness while reducing educational costs. The authors were not able to pinpoint which part of the educational package could be excluded in order to obtain this. With more knowledge on how to educate asthmatics in relation to age, asthma severity, intellectual capacity, educational status, personality etc cost-effectiveness ratios of personally designed education programmes, for example based on pre-intervention testing, should become an important topic for future research.

The authors believe the introduction of the concept NNE is quite reasonable and beneficial. NNE has the

Table 5. - One-way sensitivity analyses on costs

\begin{tabular}{|c|c|c|c|c|}
\hline \multirow[t]{2}{*}{ Variables } & \multirow[t]{2}{*}{ Range of values } & \multicolumn{2}{|c|}{ Total costs } & \multirow[t]{2}{*}{ Mean difference } \\
\hline & & Control mean & Intervention mean & \\
\hline Time cost for those employed & $\mathrm{NOK} \cdot \mathrm{h}^{-1}$ & & & \\
\hline Base case & 106.2 & 16000 & 10500 & 5500 \\
\hline Low & $106.2 \times 70 \%$ & 15900 & 10100 & 5800 \\
\hline High & $106.2 \times 130 \%$ & 16100 & 10800 & 5200 \\
\hline Time cost for those not employed & $\mathrm{NOK} \cdot \mathrm{h}^{-1}$ & & & \\
\hline Base case & 0 & 16000 & 10500 & 5500 \\
\hline Low & $106.2 \times 70 \%$ & 16200 & 10700 & 5400 \\
\hline High & $106.2 \times 130 \%$ & 16300 & 11000 & 5400 \\
\hline Cost of educational programme & NOK & & & \\
\hline Base case & 916 & 16000 & 10500 & 5500 \\
\hline Low & Teaching costs & 16000 & 10100 & 5900 \\
\hline High & Teach costs $\times 2$ & 16000 & 10600 & 5400 \\
\hline Production loss & $\mathrm{NOK} \cdot \mathrm{h}^{-1}$ & & & \\
\hline Base case & 106.2 & 16000 & 10500 & 5500 \\
\hline Low & $106.2 \times 70 \%$ & 12500 & 9500 & 3000 \\
\hline High & $106.2 \times 130 \%$ & 19500 & 11500 & 8000 \\
\hline Travel costs & NOK & & & \\
\hline Base case & Bus fares & 16000 & 10500 & 5500 \\
\hline Low & 0 & 15900 & 10300 & 5600 \\
\hline High & Bus fares $\times 4$ & 16200 & 10900 & 5300 \\
\hline
\end{tabular}

Cost items and differences are rounded off to nearest NOK 100. "Base case" is the assumption for the main conclusion. "Low" and "High" means low and high estimates for the assumptions. Regarding the patient education programme, the amount paid and reimbursed is exchanged with the cost of teaching when the scale of pay is used as a basis. 
advantage of conveying both statistical and clinical significance and it identifies the clinical effort required to attain a beneficial outcome. In comparison, the much used odds ratio is not helpful in clinical decisionmaking. The low NNE-figures reported here are powerful, especially compared to high NNT-figures often reported in trials testing the effects of medication.

Statistically significant differences in costs regarding GP visits and absenteeism from work, but not for the summed cost items (table 3 ) were found. A possible explanation for this could be that the statistical assumptions for nonparametric tests of comparable distributions of costs in the two groups, were not met. Besides this, statistical power could of course have been better with larger study populations. However, in cost analyses, statistically significant differences are not critical, as the most important factor is whether the precision around the estimates of costs is sufficient for the decision in hand [35]. Thus, sensitivity analyses were performed, testing reasonable low and high estimates for the assumptions without overt changes in the main conclusions. The robustness of the results are supported by the threshold analysis, revealing the low cost estimates for absenteeism from work needed (25\%), to make total costs comparable in the treatment groups. There is no simple answer as to why the present asthma education study is the first to demonstrate a dominant strategy. The most likely explanation is that the treatment plan, aimed at immediate change of medication at early symptoms/signs of exacerbation, might well influence the difference in production loss.

\footnotetext{
Acknowledgements. The authors would like to thank I.S. Kristiansen, University of Odense, Denmark and health economist $\mathrm{H}$. Husbyn, GlaxoWellcome, Oslo, Norway, for their consistent support and guidance through the maturation of this paper.
}

\section{References}

1. Anonymous. Global Initiative for Asthma (GINA). NIH no. 95-3659, p. 79, National Institute of Health 1993.

2. Smith DH, Malone DC, Lawson KA, Okamoto LJ, Battista C, Saunders WB. A national estimate of the economic costs of asthma. Am J Respir Crit Care Med 1997; 156: 787-793.

3. Barnes PJ, Jonsson B, Klim JB. The costs of asthma. Eur Respir J 1996; 9: 636-642.

4. Krahn MD, Berka C, Langlois P, Detsky AS. Direct and indirect costs of asthma in Canada, 1990. Can Med Assoc J 1996; 154: 821 -831.

5. Sullivan S, Elixhauser A, Buist AS, Luce BR, Eisenberg J, Weiss KB. National Asthma Education and Prevention Program working group report on the cost effectiveness of asthma care. Am J Respir Crit Care Med 1996; 154: S84-S95.

6. Weiss KB, Sullivan SD. Understanding the costs of asthma: the next step. Can Med Assoc J 1996; 154: $841-843$.

7. Buist AS. Cost-effectiveness of asthma management strategies. Eur Respir Rev 1995; 5: 292-294.
8. Lindgren B. The importance of self-management. Euro Respir Rev 1995; 6: $108-112$.

9. Bone RC. Goals of asthma management. A step-care approach. Chest 1996; 109: 1056-1065.

10. Boulet LP, Chapman KR, Green LW, FitzGerald JM. Asthma education. Chest 1994; 106: 184S-196S.

11. Anonymous. Practice parameters for the diagnosis and treatment of asthma. Joint Task Force on Practice Parameters, representing the American Academy of Allergy Asthma and Immunology, the American College of Allergy, Asthma and Immunology, and the Joint Council of Allergy, Asthma and Immunology. J Allergy Clin Immunol 1995; 96: 707 870.

12. Georgitis JW. The 1997 Asthma Management Guidelines and therapeutic issues relating to the treatment of asthma. National Heart, Lung, and Blood Institute. Chest 1999; 115: 210-217.

13. Kauppinen R, Sintonen H, Tukiainen H. One-year economic evaluation of intensive $v s$ conventional patient education and supervision for selfmanagement of new asthmatic patients. Respir Med 1998; 92: $300-307$.

14. Neri M, Migliori GB, Spanevello A, et al. Economic analysis of two structured treatment and teaching programs on asthma. Allergy 1996; 51: 313-319.

15. Gallefoss F, Bakke PS, Kjærsgaard P. Quality of life assessment after patient education in a randomized controlled study on asthma and COPD. Am J Resp Crit Care Med 1999; 159: 812-817.

16. Gallefoss F, Bakke PS. How does patient education and self-management among asthmatics and patients with chronic obstructive pulmonary disease affect medication? Am J Respir Crit Care Med 1999; 160: $2000-2005$.

17. Gallefoss F, Bakke PS. Impact of patient education and self-management on morbidity in asthmatics and patients with chronic obstructive pulmonary disease. Respir Med 2000; 94: 279-287.

18. Altman DG. Confidence intervals for the number needed to treat. $B M J 1998 ; 317$ : 1309-1312.

19. Quanjer PH, Tammeling GJ, Cotes JE, Pedersen OF, Peslin R, Yernault JC. Lung volumes and forced ventilatory flows. Report Working Party Standardization of Lung Function Tests, European Community for Steel and Coal. Official Statement of the European Respiratory Society. Eur Respir J Suppl 1993; 16: 5-40.

20. Jonsson B. A health economist's view. Euro Respir Rev 1995; 5: $271-274$.

21. Jones PW. Quality of life, health economics and asthma. Euro Respir Rev 1995; 5: 279-283.

22. Anonymous In: Applied Research and Communications Limited, ed. The Life Quality of Asthma. London, UK. Allen \& Hanburys, 1991; p. 1.

23. Jones PW, Quirk FH, Baveystock CM, Littlejohns P. A self-complete measure of health status for chronic airflow limitation. The St. George's Respiratory Questionnaire. Am Rev Respir Dis 1992; 145: $1321-$ 1327.

24. The Royal Social- and Health Department, editor. Pricelist DRG. Oslo, Norway, 1994.

25. Standard fee schedule for the Norwegian Medical Association including National Health Insurance Reimbursement rates and block grants. Norway, The Norwegian Medical Association, 1994; p. 3.

26. Taraldset A. Den norske Lægeforening. The 
Norwegian Medical Association's survey on reinbursements from National Health Insurance Schemes, 1992.

27. Anonymous. Anatomical Therapeutic Chemical (ATC) classification index including Defined Daily Doses (DDDs) for plain substances. WHO Collaborating Centre for Drug Statistics Methodology. Oslo, Norway, 1994.

28. Central Bureau of Statistics. Mean hourly wage rates for industrial workers. Oslo, Norway, 1994.

29. Drummond MF, O'Brien B, Stoddart GL, et al. Methods for the Economic Evaluation of Health care Programmes. Second ed. Oxford, Oxford University Press, 1997.

30. Koopmanschap MA, Rutten FF. The impact of indirect costs on outcomes of health care programs. Health Econ 1994; 3: 385-393.

31. Lang TA, Secic M, Ruff MK. How to Report Statistics in Medicine. Annotated Guidelines for Authors, Editors and Reviewers. First ed. Philadelphia, American College of Physicians, 1997.

32. Bolton MB, Tilley BC, Kuder J, Reeves T, Schultz LR. The cost and effectiveness of an education program for adults who have asthma. J Gen Intern Med 1991; 6: $401-407$.

33. Rutten-van Molken MP, Van Doorsylaer EK, Jansen MC, Kerstjens HA, Rutten FF. Costs and effects of inhaled corticosteroids and bronchodilators in asthma and chronic obstructive pulmonary disease. Am J Respir Crit Care Med 1995; 151: 975 - 982.

34. Buxton MJ. The economics of asthma - an introduction. Eur Respir Rev 1995; 6: 105-107.

35. Torrance GW, Siegel JE, Luce BR. Cost-Effectiveness in Health and Medicine. 1st ed. New York, Oxford University Press, 1996; Ch. 3: Framing and Designing the Cost-Effectiveness Analysis. pp. 54-81. 